\title{
Interconexão entre a história da graduação em enfermagem no Brasil e o pensamento ecossistêmico
}

\author{
Interconnection between the history of Brazilian nursing education and the ecosystem thoughts \\ Interconexión entre la historia de la formación en enfermería en Brasil y el pensamiento ecosistémico
}

\section{Danusa Fernandes Severo', Hedi Crecencia Heckler de Siqueira" \\ 'Universidade Federal do Rio Grande, Departamento de Enfermagem, Programa de Pós-Graduação em Enfermagem (Mestranda). Rio Grande-RS, Brasil. \\ "Universidade Federal do Rio Grande, Departamento de Enfermagem, \\ Programa de Pós-Graduação em Enfermagem. Rio Grande-RS, Brasil.}

\author{
Submissão: 02-12-2010 Aprovação: 01-04-2013
}

\section{RESUMO}

Objetivou-se resgatar, por meio de uma abordagem teórico-reflexiva, uma breve história da graduação em enfermagem no Brasil, tecendo uma relação com o pensamento ecossistêmico. Na discussão, procurou-se contextualizar a história da enfermagem brasileira, a perspectiva ecossistêmica, e a inter-relação entre elas. A reflexão permitiu abranger o significado que o elemento sistêmico do ensino superior em enfermagem estabelece com o espaço no qual se insere e como se processa a sua construção e modificações por meio dos princípios ecossistêmicos da integração, cooperação, inter-relação, interdependência e influência entre ambos.

Descritores: Programas de Graduação em Enfermagem; História; Ecossistema.

\begin{abstract}
This paper aimed to recover, through a theoretical-reflexive, a brief history of graduate nursing in Brazil, and its relationship with ecosystem thoughts. In the discussion one tried to reflect on the history of Brazilian nursing perspective grounded in the Thought Ecosystem. The reflection allowed to cover the meant that the higher education systemic element provides with the space in which it operates and how it processes its construction and modifications through the principles of ecosystem integration, cooperation, interrelation, interdependence and influence among both.
\end{abstract}

Key words: Education Nursing; Diploma Programs; History; Ecosystem.

\section{RESUMEN}

El artículo tiene como objetivo recuperar, a través de un abordaje teórico-reflexivo, una breve historia de la graduación en enfermería en Brasil, tejiendo una relación con el pensamiento ecosistémico. En la discusión, se intentó contextualizar la historia de la enfermería brasileña, el enfoque por ecosistémico, y la interrelación entre ellos. Esta reflexión permitió abarcar el sentido de que el elemento sistémico de la educación superior en enfermería proporciona el espacio en el que opera y cómo se procesa su construcción y modificaciones a través de los principios de integración de los ecosistemas, cooperación, interdependencia interrelación e influencia entre ambos.

Palabras clave: Programas de Graduación en Enfermería; Historia; Ecosistema. 


\section{INTRODUÇÃO}

As primeiras instituições de ensino superior foram instaladas a partir de 1808, por ocasião da vinda da família real para o Brasil. Entretanto, somente em 1920 (século XX,) surge a Universidade do Rio de Janeiro, hoje Universidade Federal do Rio de Janeiro, que reunia os cursos superiores da cidade, a saber: a Escola Politécnica, a Faculdade de Medicina e a Faculdade de Direito - que surgira a partir da fusão da Faculdade Livre de Direito e da Faculdade de Ciências Jurídicas e Sociais. O decreto que oficializou a universidade foi o de $n^{\circ} 14.343$, de 7 de setembro de 1920. Mas, somente a partir de 1930 ocorreu a procura pelo ensino superior devido as transformações políticas, sociais, econômicas e culturais em processo no país ${ }^{(1)}$.

Nesse contexto, a construção do saber em enfermagem no Brasil se desenvolveu em cinco fases ${ }^{(2)}$. A primeira denominava-se enfermagem pré-profissional, chamada de "modelo religioso", em que o saber era traduzido pelos procedimentos caseiros. Esse período inicia com o Brasil colônia e se estende até o final do século XIX. Os cuidados aos doentes, geralmente, eram realizados pelos escravos. Entretanto, destaca-se nesse período, a dedicação, zelo e cuidado desenvolvido aos doentes e necessitados, pelos padres Jesuítas José de Anchieta e Frei Fabiano de Cristo. A segunda caracterizava-se pelo modelo "vocacional e disciplinar" de Florence Nightingale, chamada de enfermagem moderna. Essa fase aponta, como marco inicial da enfermagem moderna, a criação da Escola de Enfermagem Anna Nery, no ano de 1922. Já a terceira fase, que se estende até os meados de 1940, consagrou-se pela passagem do capitalismo liberal para monopolista e pelo desenvolvimento industrial, assinalada pela enfermagem funcional, em que o foco era a assistência. A penúltima fase desenvolveu-se entre as décadas de 1940 e 1960, na qual a ênfase estava no trabalho em equipe e na organização de princípios científicos. E a quinta fase ocorreu no início da década de 1960, estendendo-se até os dias atuais com a criação das teorias de enfermagem ${ }^{(2)}$. Percebe-se que a enfermagem é uma profissão que, ao longo do tempo, vem escrevendo uma história permeada por conceitos e paradigmas, influenciando o ser e o fazer do profissional enfermeiro ${ }^{(3)}$.

Ao associar o "ser" e o "saber" do enfermeiro ao pensamento ecossistêmico emerge uma possibilidade de um novo "ser" e "fazer" na enfermagem. Nessa acepção, o enfermeiro integra a teia da vida e é convidado a fazer parte do cuidado de toda a natureza ${ }^{(4)}$. Pois, considera-se a teia da vida constituída de todos os elementos vivos e não vivos que fazem parte de um determinado espaço que se inter-relacionam, interdependem e se influenciam mutuamente.

Objetiva-se, neste artigo, refletir sobre a interconexão entre a história da Graduação em Enfermagem no Brasil e a perspectiva ecossistêmica, pois a história é constituída de eventos que influenciaram o "ser", o "saber" e o "fazer" da enfermagem.

\section{HISTÓRIA DA GRADUAÇÃO EM ENFERMAGEM NO BRASIL}

A primeira escola de enfermagem do mundo foi fundada em Londres em 1860, no Hospital de St. Thomas(5). O Brasil iniciou a sua caminhada histórica na formação em enfermagem no ano de 1890, por meio da criação da Escola Profissional de Enfermeiros e Enfermeiras pelo Marechal Deodoro da Fonseca, através do Decreto $n^{\circ} 791$, para fornecer mão-de-obra qualificada em todos os hospitais civis, militares e psiquiátricos.

No entanto, considera-se que a Enfermagem Moderna, fundamentada nos princípios nithingaleanos, foi inserida no Brasil em 1923, por meio da organização do serviço de enfermeiras do Departamento Nacional de Saúde Pública (DNSP), dirigido por Carlos Chagas. O ensino sistematizado tinha como objetivo formar profissionais de enfermagem que garantissem o saneamento urbano necessário para a continuidade do comércio internacional, o qual se encontrava ameaçado pelas epidemias.

Esse ensino estava sob a responsabilidade das enfermeiras da Fundação Rockfeller, convidadas para o Brasil com a finalidade de organizar o serviço de enfermagem de saúde pública e dirigir uma Escola de Enfermagem (EEnf). Essa escola foi nomeada EEnf do DNSP, criada em 1922, e iniciou suas atividades no ano seguinte. Após três (03) anos foi renomeada para Escola de Enfermagem Anna Nery, e a seguir, em 1931, ano da regulamentação do exercício e ensino da enfermagem no país, para EEnf da Universidade Federal do Rio de Janeiro. Somente em 1937, essa escola, pioneira de enfermagem brasileira, foi incorporada à Universidade do Brasil, e no ano de 1946 foi reconhecida como estabelecimento de ensino superior ${ }^{(6)}$.

Continuando nessa retrospectiva histórica, na década de 30 outras escolas de enfermagem foram criadas no Brasil: a Escola de Enfermagem Carlos Chagas, na cidade de Belo Horizonte- Minas Gerais-, em 1930; a fundação da Escola de Enfermagem da Escola Paulista de Medicina, em 1938 ${ }^{(6)}$.

Seguindo nessa linha de pensamento, cabe colocar que a expansão da quantidade de cursos de enfermagem, no Brasil, ocorreu por meio de determinantes sociais, políticos e econômicos, acompanhando as políticas educacionais e de saúde ${ }^{(7)}$. Para encontrar os motivos desencadeadores é preciso considerar a mudança ocorrida na Constituição Federal do Brasil de 1934 em relação à educação que passou a ser um direito de todos, sob a responsabilidade da família e dos poderes públicos. Por mais de uma década, ou seja, até 1945, o ministro da Educação e Saúde Pública, Gustavo Capanema Filho, promoveu uma gestão marcada pela reforma do ensino secundário e universitário. Nessa mesma época o Brasil já implantava as bases da educação nacional.

$\mathrm{Na}$ enfermagem, a Lei 775/49 regulamentou o ensino da enfermagem em todo o território nacional, tornando obrigatório o vínculo das escolas a um Centro Universitário ou a uma Faculdade de Medicina terminando, dessa forma, com as Escolas de Enfermagem isoladas ${ }^{(8)}$.

Seguindo na evolução do ensino no Brasil, é importante destacar a promulgação da Lei 5540/68, a qual estabeleceu a Reforma Universitária, de cunho funcionalista, segundo certas características das universidades americanas. Ela mudou a estrutura dos cursos e determinou que o ensino superior seria ministrado em universidades, aliando o ensino à pesquisa. Além disso, determinou que o corpo docente das EEnf passasse a ter uma maioria de enfermeiras. 
Nos anos 1970 e até meados dos 1980, o Departamento de Assuntos Universitários do Ministério da Educação e Cultura, criou um programa de expansão dos cursos de enfermagem, promovendo a criação de trinta e seis cursos superiores de enfermagem, sendo $67 \%$ (vinte e quatro) públicos e 33\% (doze) particulares ${ }^{(8)}$. No Brasil, com base nas informações do e-MEC ${ }^{(9)}$, existem, atualmente, 739 cursos de ensino superior em Enfermagem $^{(9)}$, distribuídos da seguinte forma nas regiões do País: região Norte 65, Nordeste 187, Centro-Oeste 61, Sudeste 316 e Sul 110.

\section{O CONTEXTO DO PENSAMENTO ECOSSISTÊMICO}

Um sistema é uma organização complexa, caracterizado pela existência de fortes interações ou por interações não triviais, isto é, não lineares ${ }^{(10)}$. O biólogo Bertalanffy, em 1928, ampliou a teoria do holismo de Smuts (1926), a qual consiste em um universo edificado em estruturas de complexidade crescente, para utilizá-la na ação do conceito das diferentes disciplinas e campos de atividade humana, como uma Teoria Geral de Sistemas. Essa teoria ressaltou os riscos da visão reducionista na tentativa de se explicar o todo pelo comportamento de uma de suas partes constituintes ${ }^{(11)}$. A mesma possui propriedades que só podem ser encontradas na complexidade, dessa forma, não devem ser identificadas por meio de análises ou fragmentações do todo. Ou seja, uma organização só pode ser estudada como um sistema, pois o todo é maior do que a soma das partes ${ }^{(11-13)}$.

O pensamento sistêmico fundamenta-se em três premissas básicas $^{(4,10)}$ :

$\checkmark$ Sistemas existem dentro de sistemas: cada sistema é constituído de subsistemas, que fazem parte de um sistema maior, o suprassistema. Portanto, cada subsistema pode ser detalhado em seus subsistemas e elementos componentes;

$\checkmark$ Sistemas são abertos e são caracterizados por um processo infinito de intercâmbios com o seu ambiente e realizam trocas de energia e informações, pois seus elementos interdependem, se inter-relacionam, se influenciam mutuamente, exercem intercâmbio e se energizam;

$\checkmark$ As funções de um sistema dependem de sua estrutura que deve estar de acordo com a finalidade ou objetivo que forma sua função de intercâmbio entre o conjunto de elementos que o compõem e que se relacionam por sua vez com o suprassistema.

Existem diversas propriedades de um sistema complexo, entre outras, destacam-se a homeostase, o feedback, a sinergia, a entropia. Enquanto o princípio da entropia se refere ao desgaste dos elementos, a homeostase possui a capacidade de o sistema retornar ao estado de equilíbrio pois, a sinergia existente entre os elementos, com seu efeito multiplicador, atua em conjunto para alavancar o resultado global. Entretanto, o feedback é necessário para comparar com critérios previamente instituídos com o produto da saída. Conforme a resposta obtida pelo sistema esse pode ser positivo e ou negativo. O feedback negativo ocorre quando há um desvio ao estabelecido, podendo o sistema como um todo ajustar-se ou neutralizar esse desvio.
Considera-se feedback positivo quando amplifica o nível da saída, assim permite verificar o que foi realizado para programar o que pode ser melhorado a partir do concretizado e assim fortalecer o processo como um todo ${ }^{(10)}$.

Essa teoria propagou-se por meio dos pensadores sistêmicos. O pensamento sistêmico é pensamento de processo, no qual a forma torna-se associada ao processo, à inter-relação, à interação, e os opostos são unificados por meio da oscilação. Tem-se que a construção de uma concepção sistêmica da vida deverá também ser subsidiada pelo conhecimento intuitivo que se fundamenta em uma experiência direta, não intelectual, da realidade, holística e não-linear ${ }^{(13)}$.

Permeado por esse pensamento, o ecossistema abrange a comunidade de organismos integrantes de um determinado espaço e que interagem entre si, são interdependentes, se inter-relacionam, trocam energia e se influenciam mutuamente numa troca de energia. O ser humano como elemento integrante do ecossistema, viabiliza e possibilita a construção de verdadeiras redes no espaço em que coabita, e se desenvol$\mathrm{ve}^{(14)}$. Desse modo, o ecossistema é um sistema aberto e dinâmico composto por organismos vivos e o meio com o qual e no qual interage, trocando material e energia; e se encontra, estruturado no tempo e no espaço ${ }^{(15)}$.

\section{A INTERRELAÇÃO DA HISTÓRIA DO ENSINO SUPERIOR EM ENFERMAGEM NO BRASIL E O PENSAMENTO ECOSSISTÊMICO}

Focar a profissão enfermagem neste pensamento e, em consequência, aplicá-lo, representa querer exceder a competência singular/pessoal e profissional, potencializando processos no desenvolvimento humano e, desta forma, encontrar respostas significativas na área da enfermagem/saúde que beneficie pessoas, comunidades, ambientes e infinitos sistemas. Portanto, nessa acepção o ser humano é um elemento constituinte da teia da vida. O ser humano pode ser visto como um ser multidimensional capaz de construir, destruir e reconstruir sua história, perante sua vivência com a possibilidade de agir de forma singular frente às situações que se apresentam ${ }^{(13)}$. É cabível considerar que cada um carrega dentro de si inúmeras particularidades advindas das diferentes vivências e situações, inerentes às constantes transformações sofridas e absorvidas e, as inúmeras decisões tomadas para se posicionar perante as mesmas.

Olhar o ser humano sob essa ótica multidimensional é considerá-lo um elemento integrante de um espaço que por sua vez integra outros elementos e que em conjunto formam um determinado ecossistema. Ao resgatar a História da Graduação em Enfermagem brasileira, e ao relacioná-la com o pensamento ecossistêmico, permite compreender o sentido que esse grupo profissional ocupa no ambiente e como se relaciona com os demais elementos que a integram. As inter-relações que se estabelecem entre todos os elementos constituintes do ecossistema são capazes de produzir o produto em processo por meio da integração, cooperação, inter-relação, interdependência e influência mútua.

Esse ecossistema por meio de suas propriedades de cooperação, parceria, inter-relação e interdependência são capazes 
de exercer influência mútua e, assim, construir um produto com capacidade de transformar o meio no qual se insere. Por conseguinte, para analisar a história da enfermagem do ponto de vista ecossistêmico é necessário considerá-la na totalidade que forma o seu conjunto e que se expressa por meio das relações com o ambiente-espaço com o qual age, muda e se transforma de maneira dinâmica.

Ao tomar por base a abordagem teórico-metodológica do ecossistema leva a apreender que cada curso ou escola de enfermagem, que se estabelece num determinado espaço, possui a probabilidade de receber a energia dos demais elementos integrantes, tanto vivos como não vivos e, assim, produzir as transformações necessárias para uma vida mais saudável e sustentável daquele ambiente. Enquanto se volve o olhar para o passado busca-se compreender a dinâmica utilizada para processar as modificações e transformações no espaço e, por conseguinte, compreender a possibilidade de continuar a introduzir as melhorias para tornar o espaço mais saudável.

\section{CONSIDERAÇÕES FINAIS}

Ao resgatar uma breve história da graduação em enfermagem brasileira, e ao relacioná-la com o pensamento ecossistêmico, foi possível compreender o sentido e a responsabilidade que a mesma possui frente ao grupo constituinte do espaço, como também, as suas relações e interdependências com os demais coadjuvantes transformadores deste ambiente.

Pontua-se que a energia resultante desse processo inter-relacional, expressa pela homeostase se potencializa na medida em que é capaz de se integrar, cooperar e inter-relacionar-se numa inclusão de totalidade. Esse princípio sistêmico sempre procura o equilíbrio. Assim, a totalidade potencializadora compreende a construção das ações e saberes que, no coletivo, torna-se maior do que a sua soma individual.

Em suma, o ecossistema como abordagem teórica permite que cada curso ou escola de enfermagem que se estabelece num determinado espaço conceba a probabilidade de receber a energia dos demais elementos integrantes, tanto vivos como não vivos e, assim, consegue produzir as transformações necessárias para uma vida mais saudável e sustentável daquele ambiente. Essa propriedade sistêmica de acordo com os autores sistêmicos permanece ininterrupta enquanto os sistemas se autorregulam e conseguem suprir a ação daqueles elementos que se encontram em processo de entropia interna. Refletir sobre esse processo dinâmico é útil e estimulante porque conduz o olhar para o passado e permite ancorar-se no saber/conhecimento construído para prosseguir projetando melhorias e avanços técnico-científicos para o futuro, pois o passado, o presente e o futuro se interconectam.

\section{REFERÊNCIAS}

1. Melo A M. História e memória do ensino superior no Piauí de 1930 a 1960. In: Anais do 4. Encontro de Pesquisa em Educação da UFPI - A pesquisa como mediação de prática sócio-educativas; 2006; Teresina, Brasil. Teresina: EDUFPI; 2006.

2. Meyer DE. A formação da enfermeira na perspectiva do gênero: uma abordagem sócio histórica. In: Waldow VR, Lopes MJM, Meyer DE, organizadoras. Maneiras de cuidar, maneiras de ensinar: a enfermagem entre a escola e a prática profissional. Porto Alegre: Artes Médicas; 1995. p.63-78.

3. Siqueira $\mathrm{HCH}$, Oliveira NA, Cecagno DA. Enfermagem do Rio Grande: sua história e seus feitos. Rio Grande. [Projeto de Pesquisa] -Escola de Enfermagem, Universidade Federal do Rio Grande; 2009.

4. Capra F. A teia da vida: uma nova compreensão científica dos sistemas vivos. São Paulo: Cultrix; 2006.

5. Faria HP, Coelho IB, Werneck MAF, Santos MA. Modelo assistencial e atenção básica à saúde. 2. ed. Belo Horizonte: Nescon/UFMG,Coopmed; 2010.

6. Fugerato ARF. Enfermeiras do Brasil: história das pioneiras. Rev Latino-Am Enferm [periódico na internet]. 2008 [acesso em 10 nov 2010];16(1):161-62. Disponível em: http://www.scielo.br/pdf/rlae/v16n1/pt_24.pdf

7. Barbosa TSC, Baptista SS. Movimento de expansão dos cursos superiores de enfermagem na região Centro-Oeste do Brasil: uma perspectiva histórica. Rev Eletrônica Enferm 2008;10(4):945-56.

8. Baptista SS, Barreira IA. Enfermagem de nível superior no
Brasilevidaassociativa. Rev Bras Enferm 2006;59(esp):411-6.

9. Ministério da Educação [homepage na internet]. e-MEC: instituições de Educação Superior e Cursos Cadastrados [acesso 19 mar 2013]. Disponível em: http://emec.mec.gov.br/.

10. GOMES SF. Fatores ecossistêmicos na interface com o cuidado/trabalho da equipe de enfermagem em um Serviço de Pronto Atendimento. Rio Grande do Sul. Dissertação [Mestrado em Enfermagem] -Universidade Federal do Rio Grande; 2011.

11. Nucci JC. Origem e desenvolvimento da ecologia e da ecologia da paisagem. Rev Eletrônica Geografar [periódico na internet]. 2007 [acesso 15 fev 2010];2(1):77-99. Disponível em: www.ser.ufpr.br/geografar.

12. Capra F. As conexões ocultas. São Paulo: Cultrix; 2002.

13. Siqueira $\mathrm{HCH}$. As interconexões dos serviços no trabalho hospitalar: um novo modo de pensar e agir. Florianópolis. Tese [Doutorado em Enfermagem] -Escola de Enfermagem, Universidade Federal de Santa Catarina; 2001.

14. Santos MC, Siqueira HCH, Silva JRS. Saúde coletiva na perspectiva ecossistêmica: uma possibilidade de ações do enfermeiro. Rev Gaúcha Enferm 2009;30(4):750-4.

15. Milioli G. O pensamento ecossistêmico para uma visão de sociedade e natureza e para o gerenciamento integrado de recursos. Desenvolvimento e Meio Ambiente [periódico na internet]. 2007 [acesso 15 set 2010];15:7587. Disponível em: http://ojs.c3sl.ufpr.br/ojs2/index.php/ made/rt/captureCite/11899/8395. 